\title{
Sobre a governança da cooperação internacional para o desenvolvimento: atores, propósitos e perspectivas*
}

\author{
Claire Gomes dos Santos** \\ Rosinha da Silva Machado Carrion***
}

SumÁrio: 1. Introdução; 2. Concepções e propósitos da cooperação internacional para o desenvolvimento; 3 . Desenvolvimento e suas múltiplas faces; 4. Governança da cooperação internacional e desenvolvimento: origens e atores envolvidos; 5 . ONGs e OIGs do norte, OSCs e ONGs do sul: relação de parceria ou dependência? 6. Considerações finais.

Summary: 1. Introduction; 2. International cooperation for development governance: concepts and purposes; 3 . The many faces of development; 4. International cooperation governance and development: origins and actors; 5. NGOs and IGOs from North and NGOs from South: partnership or dependence? 6. Concluding remarks.

Palavras-chave: cooperação internacional; desenvolvimento; terceiro setor.

KEY WORDs: international cooperation; development; third sector.

Este artigo tem como objetivo a proposição de um exercício de reflexão teórica sobre a governança da cooperação internacional para o desenvolvimento. Contrapõem-se neste artigo duas amplas abordagens sobre desenvolvimento (uma pautada pelo viés econômico, pela ideia de progresso e pela universalidade normativa; e outra traduzindo uma intenção normativa, embora contra-hegemônica, com relação ao

\footnotetext{
* Artigo recebido em 14 jun. 2010 e aceito em 14 abr. 2011.

** Economista. Mestre em administração. Doutoranda em administração no Programa de PósGraduação em Administração da Universidade Federal do Rio Grande do Sul (PPGA/UFRGS). Endereço: rua Santa Cecília, 1373/419, bl. B, Bairro Santana - CEP 90420-041, Porto Alegre, RS, Brasil. E-mail: clairegs@ig.com.br.

*** Doutora em administração (PPGA/UFRGS) com formação em Sociologie Clinique na Université de Paris VII (Jussieu-Sorbonne). Professora associada do PPGA/UFRGS. Endereço: rua Washington Luiz, 885, Centro — CEP 90010-460, Porto Alegre, RS, Brasil. E-mail: rsmcarrion@ea.ufrgs.br.
} 
discurso dominante sobre desenvolvimento, sendo pautada pela contextualidade local, histórica, cultural e territorial). Tende-se a acreditar que, mais do que resistirem ou pactuarem com as organizações não governamentais (ONGs) ou com as organizações intergovernamentais (OIGs) do norte, as organizações da sociedade civil (OSCs) e as ONGs do sul condescendam às estratégias das primeiras. Por essa razão é interessante identificar a maneira como essas organizações respondem ao processo de governança no seio da cooperação internacional para o desenvolvimento. Neste sentido, serão abordados concepções e propósitos da cooperação internacional para o desenvolvimento, seus antecedentes históricos e questões atuais, os variados papéis do Brasil nesse contexto, diferentes facetas do desenvolvimento, origens e atores envolvidos na governança da cooperação internacional para o desenvolvimento. Por fim, apresentam-se algumas considerações finais.

On the international cooperation for development governance: actors, intentions and perspectives

This essay aims to propose a theoretical reflection exercise on the governance of international cooperation for development. We argue about two broad development approaches (one is guided by an economic standpoint, the idea of progress and a normative universality, and the other one reflects a normative intention, although counter-hegemonic in relation to the dominant discourse on development, being guided by local, historical, cultural and territorial contextuality). We tend to believe that, rather than resist or agree with the NGOs or intergovernmental organizations from North, the civil society organizations and NGOs from South condescend to the strategies of the organizations from North. It is therefore interesting to identify how these organizations respond to the governance process within the international cooperation for development. In this sense, we will present concepts and purposes of international cooperation for development, its historical background and current issues, the varying roles of Brazil in this context, different approaches of development, origins and actors involved in governance of international cooperation for development. The article finishes with a few considerations.

\section{Introdução}

O termo "desenvolvimento", por si só, expressa um desafio intelectual por conta de sua polissemia. Sua significação mostra-se controversa visto que as diversas escolas e os diferentes autores que se ocupam em pensar sobre o tema visam, em geral, a estabelecer e a firmar o que consideram ser os parâmetros necessários para que se possa reconhecê-lo a partir de um ponto de vista teórico-ideológico específico. O mesmo ocorre com relação às concepções de "cooperação internacional e governança", ambas trabalhadas neste artigo. 
Este artigo apresenta como propósito um exercício teórico de reflexão sobre a questão da governança da cooperação internacional para o desenvolvimento. Dessa forma, a participação do terceiro setor diante dos desafios contemporâneos inerentes às relações internacionais como um todo se faz presente neste trabalho, assim como o papel desempenhado pelo Brasil com relação à cooperação internacional mais contemporaneamente. Merece destaque, ainda, a discussão sobre as estratégias relacionais entre organizações não governamentais, organizações da sociedade civil e organizações intergovernamentais, todas envolvidas com a cooperação internacional para o desenvolvimento (Dauvin, 2004; Milani e Solinís, 2002; Navarro-Flores, 2007).

Nessa procura por melhor expressar o que venha a configurar um processo de desenvolvimento, encontram-se tanto posições teóricas que dialogam entre si, quanto outras que se contrapõem por discordâncias teóricas ou por incompatibilidade epistemológica, autores que não acreditam (Esteva, 2007) e autores que negam a viabilidade (Furtado, 1974) do processo de desenvolvimento tal como ele se apresenta em sua forma dominante, com o predomínio da esfera econômica sobre todas as demais (Santos e Rodrígues, 2002).

Contrapõem-se neste artigo duas grandes linhas de pensamento sobre desenvolvimento, tendo por pano de fundo uma contraposição ideológica. A primeira é intitulada "perspectiva hegemônica de desenvolvimento". Mostra-se pautada pelo viés econômico, pela ideia de progresso, pelo otimismo que isto implica e pela universalidade normativa. Já a segunda é intitulada "perspectiva alternativa de desenvolvimento". Traduz uma intenção normativa, embora contra-hegemônica, com relação ao discurso dominante sobre desenvolvimento, sendo pautada pela contextualidade local, histórica, cultural e territorial, propondo, sobretudo, o que Santos (2009) denomina "ecologia de saberes".

Ao longo do texto serão abordados concepções e propósitos da cooperação internacional para o desenvolvimento, seus antecedentes históricos e questões atuais, os variados papéis do Brasil nesse contexto, diferentes facetas do desenvolvimento, origens e atores envolvidos na governança da cooperação internacional para o desenvolvimento, além de uma proposta de reflexão final sobre as formas relacionais entre os atores do norte e do sul envolvidos com a cooperação internacional. Por fim, apresentam-se algumas considerações finais.

\section{Concepções e propósitos da cooperação internacional para o desenvolvimento}

"Cooperação" não sustenta um conceito único e indiscutível na literatura que trata o tema. Isso porque, como bem explica Lima (2007), há uma ausência de 
definições inequívocas decorrente da vastidão conceitual ou teórica com que se abordam diferentes agentes e agências de cooperação, governamentais ou não governamentais, seus objetivos e pressupostos, entre outros elementos.

De acordo com Sánchez (2002), "cooperação" teria como propósitos assegurar a paz e promover desenvolvimento e justiça, mantendo, dessa forma, uma ordem social e política legítima. A cooperação internacional estaria fundamentada em ações que governos e organizações da sociedade civil de países distintos planejam e executam objetivando fomentar um progresso mais equilibrado e justo no mundo. Pode-se ainda fazer uma distinção entre "cooperação" e "ajuda oficial". Esta última se caracterizaria por ser um tipo de cooperação que se mantém, substancialmente, com recursos públicos dos países do norte ${ }^{1}$ (embora essa tendência esteja sofrendo mudanças já há uma década, considera-se aqui a noção habitual de cooperação em que os países do norte seriam os promotores da cooperação, enquanto os países do sul seriam os recebedores de ajuda ou o objetivo final da cooperação). Já para Afonso e Fernandes (2005), "ajuda oficial" ou "ajuda humanitária" serviria para responder a situações de emergência, não sendo entendida como um expediente que auxilie no desenvolvimento de longo prazo. Pode envolver o salvamento de vidas e a distribuição de bens de primeira necessidade, contribuindo para reduzir o sofrimento no curto prazo daqueles que foram atingidos por catástrofes, quer sejam de origem humana ou natural. Atualmente, a complexidade e o prolongamento das emergências tenderiam a provocar mais ações em termos de prevenção de novas crises, reabilitação, reconstrução e desenvolvimento, de forma que novos conflitos possam vir a ser evitados. Em razão destas mudanças, "ajuda humanitária" e "ajuda para o desenvolvimento" passaram a ser confundidas em algumas situações.

Segundo Sánchez (2002), a melhoria das condições de vida dos que constituem o público-alvo da cooperação usualmente ocorreria mediante a introdução de mudanças econômicas, políticas e sociais relacionadas, entre outras coisas, com o fomento dos direitos humanos, a consolidação da democracia e o estímulo de valores e atitudes a favor da paz e da solidariedade. Todas essas recomendações relacionadas à cooperação somente seriam possíveis em razão da existência de uma ampla rede de organizações nacionais e inter-

\footnotetext{
${ }^{1}$ Norte e sul, no sentido atribuído neste artigo teórico, referem-se de maneira metafórica, respectivamente, ao grupo de países entendidos como "desenvolvidos" ou ricos, e ao grupo de países entendidos como "em desenvolvimento", pobres ou politicamente periféricos, ou ainda "oprimidos pelas diferentes formas de dominação colonial e capitalista" (Santos, 2009:13).
} 
nacionais de natureza pública, bem como de natureza privada (tendo como origem a sociedade civil), rede esta que integraria o que se conhece por "sistema de cooperação internacional”. Já para Amorim (1994), um dos principais pressupostos da cooperação internacional seria a ideia de "alteridade", isto é, de respeito de um Estado pelos demais Estados, oportunizando que cada um possa traçar seus próprios objetivos, no que se deposita a ideia de independência e soberania. De acordo com o autor, subjacente a esse equilíbrio de poder, a intenção que se apresenta privilegiaria antes a manutenção de certa ordem mundial do que propriamente a paz.

Para fins da reflexão teórico-conceitual apresentada neste artigo, cooperação internacional ainda pode ser considerada por meio de dois enfoques, diferenciados entre "tradicional" e "moderno" (Sánchez, 2002). O enfoque "tradicional" costuma ser associado aos primórdios da cooperação, iniciada logo após a Segunda Guerra Mundial e tendo se estendido por todo o período da Guerra Fria (1945-89). Seus objetivos e métodos de trabalho tendem a ser colocados pelo país que oferta os recursos financeiros, havendo um acordo marcado por interesses ligados a questões de segurança nacional no período da Guerra Fria. Já o enfoque entendido como "moderno" tem seu marco inicial após a Guerra Fria, momento em que as organizações civis começaram a despontar com maior vigor e a reivindicar mudanças na forma como até então se concebia a cooperação. Em outras palavras, passa-se a propor certa concertação entre doadores e receptores dos recursos envolvidos na cooperação de forma que todos possam trabalhar em conjunto ao projetar e executar um plano de ação (a chamada "parceria"). Dessa maneira, espera-se que ocorra a substituição (ao menos parcial, e não apenas no plano do discurso) da relação anteriormente usual de dominação por outra em que possam existir associação e compartilhamento de responsabilidades entre os atores envolvidos.

Para fins de diferenciação, é relevante salientar a motivação fundamental associada a cada um dos dois enfoques de cooperação acima apresentados. A base do modelo "tradicional" se encontra sobre a caridade, ${ }^{2}$ uma vez que a ajuda se daria por misericórdia e a cooperação ocorreria de forma a não questionar a origem das injustiças nem em tentar alterar o status quo. Já o modelo "moder-

\footnotetext{
${ }^{2}$ A caridade cristã e a filantropia têm suas raízes ancoradas em duas diferentes tradições, embora atuando de maneira semelhante. A caridade cristã visa mais à alma que ao corpo de quem é beneficiado, desconsiderando o homem como um sujeito social e histórico, mas apenas como "filho de Deus", um ser universal. Já a filantropia faz apelo à razão, tendo nascido às vésperas da Revolução Francesa, pelas mãos de banqueiros, industriais e altos funcionários, com o sentido de remediar os danos causados pelo progresso da Revolução Industrial, então vigente (Freyss, 2004:743).
} 
no" de cooperação teria seu fundamento sobre a promoção da justiça e buscaria transformar a realidade social. Diferentemente do enfoque tradicional, o enfoque moderno de cooperação dedicar-se-ia a problemas imediatos sem descuidar de suas causas, de forma que atuaria, nesse contexto, de maneira a sustentar-se no tempo. O enfoque moderno de cooperação pressupõe, ainda, um modelo de desenvolvimento distinto daquele que se ajustaria à concepção tradicional de cooperação (Sánchez, 2002), os quais discutiremos mais adiante.

\subsection{Antecedentes históricos da cooperação internacional para o desenvolvimento}

Embora Lima (2007) afirme que a cooperação internacional tenha origens diversas, uma vez que sua natureza também seria múltipla (haja vista a existência de organizações de cunho religioso, não governamental, governamental etc. atuando com cooperação), uma versão prevalece a respeito de sua origem. Ayllón (2007) explica que o surgimento da cooperação internacional no quadro do sistema de relações internacionais teria sido posterior à Segunda Guerra Mundial e que não teria sido fruto (ao menos exclusivamente) de motivações éticas ou humanitárias. A preponderância de uma conjuntura geopolítica determinada pela divisão bipolar do mundo é que teria condicionado o nascimento deste tipo de cooperação. Após as duas grandes guerras do século $\mathrm{XX}$, foram criadas instituições no sentido de se consolidar uma rede de cooperação entre os estados e, posteriormente, encontros em que grandes potências mundiais teriam se reunido. Contudo, os temas econômicos ganharam destaque no traçado institucional em decorrência das recorrentes crises no período entre guerras, momento em que teria havido recessão, elevadas taxas de desemprego e restrições ao comércio. O Banco Mundial, por exemplo, teria nascido com fins de reconstrução. Somente em consequência do esforço de líderes latino-americanos teria sido possível incluir entre os objetivos do banco também o "desenvolvimento". Assim, conforme elucida Amorim (1994), só tardiamente (e de maneira incompleta) o desenvolvimento (prioridade dos países mais pobres) inscreve-se como desafio aos projetos de cooperação, juntamente com a manutenção da ordem e da paz.

Com a criação da Comissão Econômica para a América Latina e o Caribe (Cepal) e sua produção intelectual decorrente, o processo de descolonização dos países africanos e asiáticos (novos estados independentes, aos quais seria atribuído o status de "subdesenvolvidos") e o nascimento de focos de tensão em países periféricos como Indochina (região que compreendia os atuais 
Vietnã, Laos e Camboja), Argélia, Cuba e Congo, a questão do desenvolvimento passa a se destacar, apontando para uma realidade em que vigorava um sistema de relações internacionais desigual, o que suscitaria uma discussão a respeito das causas do "subdesenvolvimento" desses países. Para bem exemplificar a discussão sobre o tema no âmbito da América Latina, Amorim (1994) relembra um ensaio de 1949, em que o economista argentino Raúl Prebisch teria retratado a impossibilidade de a América Latina (e de países periféricos em geral) alavancar seu próprio progresso e, consequentemente, tomar para si os resultados desse processo.

Até a década de 1980, a ajuda internacional era vista como um fator desencadeador de desenvolvimento (Afonso e Fernandes, 2005). Ao contextualizar as relações internacionais no período após a Guerra Fria, Halliday (2007:231) apresenta da seguinte maneira um panorama que retrata o final dos anos 1980 e início dos anos 1990: "um sistema hegemônico e a sua correspondente distribuição de poder desmoronaram. O mapa dos Estados foi redesenhado e cerca de vinte novos Estados soberanos foram criados. Um grau de incerteza sem paralelos desde a década de 1930 prevaleceu na arena internacional".

Nos anos 1990, a preocupação teria se direcionado ao ambiente político e estrutural dos estados porque se entendeu que, sem uma adequação nesse sentido, recursos poderiam ser desperdiçados em projetos que não visavam ao longo prazo. Os recursos provenientes da ajuda internacional começariam, então, a ceder lugar de maneira a privilegiar os fluxos de capital privado. Isso porque a responsabilidade pelo processo de desenvolvimento dos países passaria a ser por eles internalizada por conta da forte influência da ideologia neoliberal dominante a partir deste momento (Halliday, 2007).

A partir dessa visão sobre o período, duas perguntas sobre as condições futuras das relações internacionais ainda demandavam por respostas. A primeira delas questionava se o fim da Guerra Fria marcaria também o fim da rivalidade militar entre os grandes poderes no mundo como um todo (ao menos pelo período de uma geração); a segunda, se haveria o surgimento de uma nova figura representada por outro conjunto de blocos interestatais de poder, estabelecendo, assim, uma nova hegemonia (Halliday, 2007).

\subsection{A cooperação internacional para o desenvolvimento nos dias de hoje}

Ainda na década de 1990, a ajuda teria começado a ser destinada com maior intensidade a melhorias de infraestrutura e serviços sociais de base, como 
saúde, educação, saneamento, entre outros (setores onde o mercado não exerceria influência), no sentido de assegurar um investimento que tivesse em vista o desenvolvimento a longo prazo. Na segunda metade dos anos 1990 teria havido uma forte transição de economias anteriormente planejadas para economias de mercado. Além disso, a crise financeira asiática, em 1997, e o desencadeamento de outras crises na América Latina e na Rússia teriam provocado a inversão das tendências de longo prazo de redução da pobreza, fazendo com que esta temática reaparecesse como o principal objetivo da ajuda para o desenvolvimento (Afonso e Fernandes, 2005).

O papel do Estado e do mercado, juntamente com o debate sobre as instituições para a aceleração do processo de desenvolvimento (suas regras e seus procedimentos), passa a representar uma questão central, devido às circunstâncias. A atribuição dos papéis de regulação e de Estado-providência veio responder quanto à forma com que o Estado deveria se portar. Ao mesmo tempo, passou-se a compreender e a debater sobre a possibilidade de a cooperação, ao transferir recursos e tecnologias para localidades receptoras de ajuda, transportar valores e elementos culturais (explícita ou implicitamente), podendo alterar, em alguma medida, as realidades socioculturais destas regiões mais vulneráveis (Afonso e Fernandes, 2005).

A sociedade, então, viria a enfrentar a rigidez das instituições na tentativa de concretizar novos processos de desenvolvimento, principalmente em muitos países periféricos, onde as instituições ainda se caracterizariam por certas disfunções burocráticas, refletindo graus variados de autoritarismo e falta de transparência nas relações com a sociedade. Salienta-se o caráter de flexibilidade que deveria estar necessariamente atrelado às instituições, haja vista que aquelas que tiveram papel relevante no passado não necessariamente terão papel de destaque no futuro. Nesse sentido, torna-se imprescindível pensar a construção de novas formas de articulação entre as esferas governamental, da sociedade civil e dos agentes produtivos com o intuito de se buscar uma maior adequação desse conjunto aos processos de desenvolvimento de cada sociedade (Arns et al., s.d.). Conforme Arns e colaboradores (s.d.:8):

no atual momento do desenvolvimento da humanidade, os territórios e instituições estão sendo testados em sua capacidade de adaptação e parece ter se reduzido o espaço para estruturas de dominação através do paternalismo/clientelismo, abrindo espaço para novas formas menos hierárquicas, mais críticas, flexíveis e autônomas. O estágio evoluído da autonomia é alcançado através da intensificação da solidariedade, da cooperação, da confiança, da comunicação, da participação, e da corresponsabilidade. 
As instituições passam a se constituir a partir de processos resultantes de consensos, de projetos coletivos e de ações cooperadas. Essa "concertação" é esperada para que se cumpra o compromisso da articulação no âmbito institucional, tão necessária para a administração de conflitos e para a integração de ações de apoio ao desenvolvimento (Arns et al., s.d.). No entanto, para além das fronteiras teóricas, é necessário afirmar que a divisão entre os diferentes enfoques de cooperação não é muito clara. Isto porque, na prática, o enfoque tradicional ainda tem prevalecido sobre o moderno (haja vista a indubitável dominação política presente mesmo nas ações de parceria entre os países, como salientado por Navarro-Flores, 2007), embora exista uma tendência crescente de rompimento com alguns valores do passado. A evolução da cooperação internacional aponta, por exemplo, para uma crescente cooperação entre os países em desenvolvimento, abandonando relações verticais por relações horizontais (a chamada cooperação sul-sul) desde a década de 1990 (MRE, 2008).

Embora exacerbada nos tempos atuais, o alcance de algumas características da globalização (como a divisão centro/periferia e o cumprimento dos princípios de livre-mercado e dos regramentos acordados pelo Consenso de Washington) ${ }^{3}$ é passível de crítica (Campos, 2005; Santos, 2005). Para Sánchez (2002), por exemplo, o enfoque moderno de cooperação faz crer, ao menos em parte, num modelo de desenvolvimento distinto do que se ajusta ao enfoque tradicional de cooperação. Sánchez tece algumas conclusões que tenderiam a complexificar as concepções de hoje sobre cooperação para o desenvolvimento, governança, terceiro setor e a relação entre estas noções. Como exemplo, Sánchez acredita não haver razão para se afirmar que a globalização constitua um fenômeno global. Isto porque, paradoxalmente, o processo por meio do qual ela ocorre seria muito seletivo: por conta de ter eleito como prediletos os campos financeiro e especulativo, além do produtivo e comercial, limitar-se-ia a conectar, umas às outras, as zonas geográficas mais dinâmicas do mundo, provocando, assim, uma maior e mais profunda marginalização das demais regiões, principalmente as pobres e excluídas (Milani, 1999; Milani e Solinís, 2002; Sánchez, 2002). Santos (2009) apresenta uma discussão em torno da globalização que complementa o posicionamento de

\footnotetext{
${ }^{3}$ Conjunto de regramentos calcados no paradigma neoliberal que garantiu a sustentação de políticas visando à sustentação da agenda pró-mercado e do estado mínimo na esfera internacional ao longo dos anos 1990. Resumidamente, seu receituário baseava-se na livre atuação do mercado, no predomínio da abertura para o comércio internacional, no ajuste das contas públicas, na redução dos gastos com políticas sociais, nas privatizações, entre outros (Campos, 2005:8).
} 
Sánchez (2002), uma vez que traz a ideia de que existam tipos contextuais de globalização. Afinal, os princípios de livre-mercado e os regramentos do Consenso de Washington não povoam (ao menos ainda) todas as relações de todos os grupos sociais em escala global, embora representem a ideologia dominante ou o pensamento hegemônico atual. O estágio atual da forma de globalização dominante não estaria a ajudar de forma alguma os países do sul, muito menos a alcançar o "desenvolvimento". Somente por meio de uma concepção de globalização democrática — no sentido mais amplo da palavra, ao possibilitar e promover espaços de discussão, com liberdade política plena - e plural - ao reconhecer conhecimentos e saberes relegados a um segundo plano pelos cânones do pensamento dominante, ao que Santos (2009) intitula uma "ecologia de saberes" - haverá eco para uma perspectiva alternativa de desenvolvimento, como a que será discutida adiante.

\subsection{O Brasil e seus diferentes papéis na cooperação internacional para o desenvolvimento}

Atualmente, há uma pluralidade no que diz respeito às formas com que vêm ocorrendo ações de cooperação internacional envolvendo o Brasil (MRE, 2008). Se, por um lado, há muitas articulações identificadas como "parcerias" (seja em termos de financiamento ou de intercâmbios de técnicas, conhecimentos, pessoas qualificadas etc.), por outro lado, também é possível encontrar no território brasileiro (bem como em todo o mundo) muitas iniciativas de "ajuda internacional", envolvendo organizações não governamentais (ONGs), universidades, igrejas de diferentes credos, entre outros (Lima, 2007). O que escapa ao modo de colaboração identificado mais contemporaneamente como de parceria, em que se propõe troca de experiências, conhecimentos e responsabilidades, embora esses intercâmbios não pressuponham, necessariamente, uma relação de poder mais igualitária na prática (Navarro-Flores, 2007).

As relações internacionais do Brasil com o exterior já apresentam há uma década diversas tratativas bilaterais, e mesmo multilaterais, com países do sul. A ampliação das relações horizontais do Brasil com o exterior ocorreria, segundo a Agência Brasileira de Cooperação (ABC) (MRE, 2008), por conta das oportunidades de troca de experiências num ambiente onde as nações partícipes compartilham realidades mais próximas, muitas vezes muito diversas daquelas dos países do norte. Principalmente, em se tratando de compartilhar com outros países que ainda apresentem carência de instituições 
mais desenvolvidas (instituições nacionais tecnicamente capacitadas na área de administração pública, de planejamento, de ciência e tecnologia etc.) os frutos do apoio técnico e financeiro ocorrido no passado por parte de nações doadoras do norte.

O Brasil teria sido beneficiado ainda na primeira fase da cooperação multinacional (por volta de 1950), tendo resultado dessa iniciativa os alicerces de diversas instituições de destaque no cenário nacional por serem elementos de relevância crucial para a estruturação do país, como a Empresa Brasileira de Pesquisa Agropecuária (Embrapa), o Serviço Nacional de Aprendizagem Industrial (Senai) e a Fundação Oswaldo Cruz (Fiocruz). Com o passar dos anos, conforme salientado pela ABC (MRE, 2008), o Brasil teria empreendido experiências de sucesso, dando continuidade a essas e a outras iniciativas bem-sucedidas, o que o capacitaria para instigar o princípio desse mesmo processo em outros países.

Ademais, organismos internacionais, como Nações Unidas e Banco Mundial, estariam demandando a presença mais direta do país em situações como negociação de paz e outras associadas a regiões afetadas por guerras no mundo (como os casos do Timor Leste e do Haiti). De acordo com a ABC, essas demandas teriam surgido aos poucos, enquanto a própria política externa brasileira também sofria mudanças, passando da chamada "política de luta pelo poder" (então prevalecente entre todas as nações) para uma "diplomacia da solidariedade". Por esta última perspectiva, a cooperação internacional teria passado a ser considerada uma forma de estabelecer princípios de corresponsabilidade por meio da cooperação sul-sul ainda ao final da década de 1970.

Amorim (1994) destaca alguns pontos a serem considerados para que o Brasil, assim como outros países periféricos, possa se valer da cooperação internacional como forma de melhorar sua condição socioeconômica. Primeiramente, Amorim acredita que a cooperação internacional não pode ser encarada como alternativa para o esforço interno, como fonte exclusiva ou principal de desenvolvimento. Isto porque esta escolha implicaria condenar-se à dependência e à submissão. Em segundo lugar, a cooperação só será verdadeiramente frutífera quando houver complementaridade real de interesses. Em terceiro lugar, a ampliação das ações cooperativas do terreno científico para o tecnológico envolve adaptações e ajustes no aparelho institucional que não estão totalmente resolvidos. Por fim, Amorim crê que a cooperação em ciência e tecnologia não deva ocorrer de forma isolada do conjunto das relações internacionais do país, havendo a necessidade de uma aliança de interesses visando ao futuro. 


\section{Desenvolvimento e suas múltiplas faces}

O termo "desenvolvimento", por si só, expressa um desafio intelectual por conta de sua polissemia. Sua significação mostra-se controversa visto que as diversas escolas e os diferentes autores que se ocupam em pensar sobre o tema visam, em geral, a estabelecer e a firmar o que consideram os parâmetros necessários para que se possa reconhecê-lo a partir de um ponto de vista teórico específico. Nessa procura por melhor expressar o que venha a configurar um processo de desenvolvimento, encontram-se tanto posições teóricas que dialogam entre si quanto outras que se contrapõem por discordâncias teóricas ou por incompatibilidade epistemológica, autores que não acreditam (Esteva, 2007) e autores que negam a viabilidade do processo de desenvolvimento tal como ele se apresenta em sua forma dominante, com o predomínio da esfera econômica sobre todas as demais (Furtado, 1974; Santos e Rodrígues, 2002).

Em suas origens, o termo "desenvolvimento" surge ao expressar uma orientação apresentada em termos de uma necessidade evolucionária (Rostow, 1974) e como uma lei natural a ser perseguida por todas as nações (a partir das experiências de países tidos como desenvolvidos), independentemente de sua posição geográfica no globo ou de seu processo histórico. A lógica racionalista engendrada pelos avanços da ciência a partir do século XVIII, que se associava ao poder da técnica para promover a evolução constante da humanidade, ao oferecer conhecimento ilimitado sobre o mundo, orientou a formação desenvolvimentista naquele período (Campos, 2005), pautando-se por uma racionalidade de cunho ocidental e por uma pretensa neutralidade científica que ainda hoje buscam se furtar de quaisquer alternativas ao classificá-las como "primitivas, retrógradas, irracionais ou ingênuas" (Tucker, 1999:2).

Consolidou-se a ideia racional de "certeza", então possível em decorrência das novas capacidades de previsão descortinadas pela ciência moderna. Nesse sentido, o desenvolvimento poderia ser entendido (de acordo com uma metáfora biológica) como um processo a partir do qual as potencialidades de um objeto ou organismo fossem libertadas para atingir sua expressão completa, entendida como algo natural. Entre os séculos XVIII e XIX, a compreensão do desenvolvimento biológico passou a ser percebida como uma transformação no sentido de uma forma mais "perfeita". Dessa maneira, "evolução" e "desenvolvimento" seriam termos intercambiáveis pelos cientistas naquela ocasião, passando também a ser utilizados na esfera social no final do século XVIII (Esteva, 2007).

Como resultado da extensão da racionalidade científica para outras esferas da vida, a intervenção humana planejada pelos termos de pensadores 
liberais, como Walt Whitman Rostow, apontava para estágios específicos no tempo, necessários de serem alcançados como forma de escapar à ameaça soviética. De acordo com a teoria de Rostow (1974) sobre as "cinco etapas do desenvolvimento", este se desenrolaria segundo cinco grandes fases: a sociedade tradicional (todo o mundo considerado pré-newtoniano), as condições prévias à decolagem (fase de transição, com a exploração dos frutos da ciência), a decolagem (grandes investimentos, principalmente na indústria), o progresso em direção à maturidade (extensão da tecnologia moderna para toda a economia, longo período de progresso continuado) e a era do consumo de massa (transferência de grandes investimentos para a produção de bens duráveis de consumo e serviços), a qual representaria o estágio máximo do capitalismo liberal, tendo como modelo o american way of life (Rostow, 1974).

Diversas dimensões têm sido trabalhadas no sentido de trazer a discussão sobre o desenvolvimento para campos complementares das ciências sociais, enriquecendo o debate. Duas grandes linhas de desenvolvimento devem ser abordadas. A primeira, aqui identificada como "perspectiva hegemônica de desenvolvimento", mostra-se pautada pelo viés econômico, pela ideia de progresso, pelo otimismo que isto implica e pela universalidade normativa. Já a outra linha, aqui identificada como "perspectiva alternativa de desenvolvimento", traduz uma intenção normativa, embora contra-hegemônica, com relação ao discurso dominante sobre desenvolvimento, pois é pautada sobre práticas, atores e relações sociais, assim como pelo contexto local, exigindo um olhar particular sobre cada situação avaliada e respeitando questões históricas, culturais e territoriais (Santos, 2005, 2009; Santos e Rodrígues, 2002). Ao defender o que chama de "ecologia de saberes", Santos (2009:9) tece argumentos em favor da "interculturalidade", um conceito que traduz em boa parte as diferenças de percepção quanto a questões culturais e políticas:

Ao contrário do multiculturalismo - que pressupõe a existência de uma cultura dominante que aceita, tolera ou reconhece a existência de outras culturas no espaço cultural onde domina - a interculturalidade pressupõe o reconhecimento recíproco e a disponibilidade para enriquecimento mútuo entre várias culturas que partilham um dado espaço cultural.

A economia deveria ser percebida como uma esfera dependente da vida social, enfatizando a necessidade de discerni-la como uma fração elementar da sociedade, embora subordinada a imperativos não econômicos, como a igualdade e a cidadania. Dessa forma, o usufruto dos resultados do desenvolvimento seria, então, disseminado plenamente por entre todos os sujeitos partícipes 
da sociedade, particularmente entre os grupos marginalizados, privilegiando o desenvolvimento a partir da base (bottom-up) (Santos e Rodrígues, 2002). Assim como Furtado (1974), entende-se que o processo de desenvolvimento visto como evolução estrutural do sistema capitalista não apresenta viabilidade. Para o referido autor, este processo constitui um "mito" na medida em que preconiza que os países em desenvolvimento deveriam perseguir uma sequência de fases historicamente determinadas (Rostow, 1974) com o intuito maior de alcançar o padrão de consumo dos países industrializados.

\section{Governança da cooperação internacional e desenvolvimento: origens e atores envolvidos}

Enquanto cooperação internacional tem sido um assunto pouco explorado no campo de conhecimentos da administração, o tema "governança", entretanto, tem-se mostrado recorrente nos estudos da área (Arturi e Oliveira, 2002; Carrion e Lopes, 2004; Milani e Solinís, 2002). Arturi e Oliveira (2002), por exemplo, introduzem um conjunto de artigos em que o tema da governança é apresentado por diferentes perspectivas, salientando a necessidade de uma "mundialização positiva" por meio da formação de redes, ao vincular organismos internacionais, governamentais, ONGs e o setor privado com o sentido de formar espaços privilegiados de discussão e pesquisa sobre o tema. Já Carrion e Lopes (2004), por sua vez, debruçam-se sobre as falhas de governança ocorridas num projeto que apresentava como pano de fundo uma central de comercialização de matéria-prima para o setor de reciclagem em Porto Alegre (RS), o qual envolveu tanto atores dos galpões de triagem quanto o poder público, ONGs e mesmo uma universidade em diversos conflitos. Por fim, Milani e Solinís (2002) são vistos com maior atenção na sequência do trabalho.

Segundo Herz e Hoffmann (2004), os atores institucionais habitualmente presentes no palco da cooperação internacional para o desenvolvimento seriam as organizações intergovernamentais (OIGs) (formadas por estados e geralmente associadas ao Hemisfério Norte) e as organizações não governamentais (ONGs) (no contexto da cooperação internacional, geralmente associadas ao Hemisfério Sul). As autoras salientam que a rede de organizações internacionais participa de um conjunto maior de instituições que garantem, de certa maneira, uma parcela da "governança global" (Herz e Hoffmann, 2004:18) por meio de normas, regras, leis, procedimentos para a resolução de disputas, ajuda humanitária, utilização da força militar, programas de as- 
sistência ao desenvolvimento e mecanismos para coletar informações, entre outras práticas.

Milani e Solinís (2002) remontam à origem do termo "governança", que seria marcado pela teoria das firmas e pela chamada corporate governance ao fazer referência ao artigo de Ronald Coase de 1937, intitulado The nature of the firm. Segundo Milani e Solinís, esse artigo, somente retomado em sua importância na década de 1970 por Oliver Wiliamson, faria referência à descrição de protocolos para conduzir coordenações eficazes em dois sentidos: a) os protocolos internos, quando a firma desenvolve suas redes e questiona as hierarquias internas; b) os contratos e as aplicações de normas, quando a firma se abre à terceirização (Milani e Solinís, 2002:271). Em resumo, o artigo seria uma apologia ao uso da governance corporativa (em diferentes variações de contexto) no sentido de propor organizações em rede e globais em detrimento de organizações hierarquizadas e integradas verticalmente. Em 1975 (época marcada pelo início da crise do Estado-providência), o tema da "governabilidade" foi o centro das discussões em um relatório da chamada Comissão Trilateral (composta por representantes da Europa Ocidental, Japão e Estados Unidos), em que se chamava a atenção para a situação de aumento das demandas sociais e de falta de recursos do Estado, a que se propunham tanto mudanças por parte das instituições (retração da máquina estatal), como por parte do comportamento dos cidadãos. Nesse sentido, os atores não estatais passariam a ganhar maior legitimidade no que tangia à promoção e à defesa do bem público, colocando por término a exclusividade do Estado no que dizia respeito a estas questões e abrindo espaço para a discussão em torno de uma nova definição de espaço público, constituído de uma rede complexa de interesses e de interações (Milani e Solinís, 2002:272).

No final da década de 1980, a dicotomia "má governança versus boa governança" teria ganhado espaço por meio do discurso do Banco Mundial em alguns de seus relatórios na década de 1990, que responsabilizariam os países em vias de desenvolvimento pela "má governança" associada aos fracassos na implementação de programas de ajuste estrutural (PAS). Isso teria justificado a defesa de uma reforma nas administrações desses países no sentido de que eles pudessem responder às exigências associadas à eficácia e à rentabilidade financeira dos PAS (Milani e Solinís, 2002). Na literatura acadêmica, em geral, "governança" tende a ser caracterizada como um processo complexo de tomada de decisão que anteciparia e ultrapassaria o governo, e os aspectos mais evidenciados seriam associados:

à legitimidade do espaço público em constituição; à repartição do poder entre aqueles que governam e aqueles que são governados; aos processos de negocia- 
ção entre os atores sociais (os procedimentos e as práticas, a gestão das interações e das interdependências que desembocam ou não em sistemas alternativos de regulação, o estabelecimento de redes e os mecanismos de coordenação); e à descentralização da autoridade e das funções ligadas ao ato de governar (Milani e Solinís, 2002:273).

Por sua vez, relativamente à "governança global", Herz e Hoffmann (2004) lembram que uma conceituação teria surgido no relatório da Comissão sobre Governança Global de 1995, por ocasião da comemoração dos cinquenta anos de fundação da Organização das Nações Unidas (ONU). Essa comissão seria composta por um grupo independente de 28 líderes e pensadores de diversas partes do mundo, com responsabilidades e experiências diversas. A tarefa do grupo teria sido a de sugerir caminhos por meio dos quais a "comunidade global" poderia melhor administrar os desafios comuns entre si com a chegada do novo milênio. Como resultado de seus dois anos e meio de trabalho, foi produzido um relatório em forma de livro intitulado Nossa comunidade global. Neste relatório, governança é definida como: "A totalidade das diversas maneiras pelas quais os indivíduos e as instituições, públicas e privadas, administram seus problemas comuns. É um processo contínuo pelo qual é possível harmonizar interesses conflitantes ou diferentes, e realizar ações cooperativas" (Comissão, 1996:2).

A "governança global" extrapola uma proposta de governo mundial, embora questões relativas à soberania dos estados e à representatividade dos países e de seus governos na política internacional sempre participem do debate, chegando-se a questões relativas a uma possível sugestão de um "estado mínimo" e sobre as obrigações do Estado. A ênfase da governança global está na busca de valores comuns, de uma ética cívica global e de uma liderança inovadora para guiar os povos e nações da intitulada "comunidade mundial". Para tanto, oferece como propostas promover a segurança dos povos e do planeta, gerenciar a economia global, reformular a Organização das Nações Unidas (ONU) e garantir a aplicação das leis na esfera mundial, com as medidas pretendidas não sendo garantidas por uma autoridade formal (Herz e Hoffmann, 2004). Ademais, desde o fim do bipolarismo característico da Guerra Fria, o cenário internacional apresentaria a necessidade de uma nova ordem mundial mais justa, sobretudo atualmente quando o que se percebe é a verticalização das hierarquias de poder, a disputa entre as nações, além de relações estratégicas e militares que aprofundam os conflitos internacionais agravados em parte pelas políticas neoliberais postas em prática com a rubrica de instituições financeiras e comerciais internacionais (Arturi e Oliveira, 2002). 
É controverso debater sobre as nuances ideológicas que gravitam em torno das concepções de "desenvolvimento" e de "governança" associadas à cooperação internacional. Isto porque a discussão aborda elementos que dizem respeito a seus pressupostos, assim como às condições (históricas, políticas, culturais etc.) em que se constrói a concepção de desenvolvimento subjacente às práticas de cooperação internacional. Nesse sentido, segundo Milani e Solinís (2002), as análises críticas em torno do termo "governança" apontam, atualmente, para a relativização do intergovernamentalismo. Em outras palavras, haveria uma forte tendência a que as organizações intergovernamentais produzam problemas de monta ao falharem em oferecer respostas a problemas do cotidiano de cidadãos e por não adequarem projetos globais de cooperação internacional a realidades locais. Essas dificuldades acarretariam, por consequência, a ampliação de outras demandas por participação política na esfera não governamental, assim como também a própria concepção de governanças híbridas, no sentido de se ignorar uma divisão maniqueísta entre o que venha a ser uma "boa" ou "má" governança. Isto é, sem que seja possível separarem-se claramente características devidas às origens de uma governança baseada nas firmas e no mercado, ou baseada no fortalecimento do Estado e na renovação das organizações intergovernamentais.

\section{ONGs e OIGs do norte, OSCs e ONGs do sul: relação de parceria ou dependência?}

É importante identificar a maneira como as organizações da sociedade civil (OSCs) e as ONGs do sul respondem ao processo de governança no seio da cooperação internacional para o desenvolvimento uma vez que se tem como ideia inicial que elas, mais do que resistirem ou pactuarem com as ONGs ou com as OIGs do norte, condescendem às estratégias das últimas (Dauvin, 2004; Milani e Solinís, 2002). Esse juízo se deve ao processo de tomada de decisões nas ONGs e OIGs internacionais que, indubitavelmente, desenrolase tendo como pano de fundo o poder hegemônico de certos estados. Ora, considera-se aqui que a hegemonia não se faria representar apenas em termos financeiros, materiais ou tecnológicos, mas, também, e de forma inquestionável, no campo ideológico. Por outro lado, as OSCs e as ONGs do sul, tendo em vista sua heterogeneidade crescente, não necessariamente compartilham os mesmos valores. A própria forma de legitimidade com que cada grupo se mantém em seu campo de atuação pode ser diferente. Com relação às associações locais, organizações e sindicatos (exemplos do que convencionalmente pode- 
mos intitular como OSCs), predomina a proximidade com o público atendido em razão dos objetivos que se propõem a realizar e por conta da eficácia na prestação de serviços sociais realizados, como: prestação de serviços básicos de urgência, projetos de desenvolvimento, organização das comunidades na identificação e avaliação das necessidades locais e apoio à política dos governos locais. Já as ONGs fazem valer seu objetivo de existência, ou pelos mesmos expedientes do que aqui convencionamos por chamar de OSCs, ou por meio de atividades de informação (pesquisa e denúncia), mobilização social, ação normativa (elaboração de normas e regulamentação) e ação operacional (gestão de projetos e responsabilidade na execução de políticas sociais) (Milani e Solinís, 2002:283).

Relativamente à relação que se construiu entre as OSCs ou ONGs locais e as ONGs internacionais (sobretudo as do norte) a partir da década de 1980, teria havido uma mudança significativa ao se evoluir de uma relação doadores-beneficiários para uma parceria fundamentada sobre objetivos comuns. Evolução esta que, no entanto, teria ocorrido de maneira bem mais intensa no plano da retórica. A capacidade de financiamento de projetos, particularmente em regiões de algum interesse por parte das ONGs internacionais, no entanto, continua a moderar todo o processo. Dessa forma, as ONGs ou as OIGs financiadoras terminam por definir as regras às quais as OSC e ONGs do sul devem se submeter se desejarem participar dessa relação, ao que também se impõe uma necessidade de alinhamento a critérios de gestão (relativos à chamada "boa governança") diante da pena de exclusão (Dauvin, 2004).

Navarro-Flores (2007), por sua vez, salienta que esse paradoxo traduz, na verdade, um compromisso no qual os atores do norte (as OIGs) e do sul (as ONGs) negociam entre si os termos de sua relação de cooperação levando em consideração as relações de poder desiguais que povoam esse compromisso, tendo em vista que os atores envolvidos teriam aprendido ao longo dos anos a atuar de forma cooperativa nesse contexto. Não se pode esquecer, contudo, que o universo das muitas ONGs existentes no sul é bastante heterogêneo, abarcando tanto aquelas que já possuem certa experiência na relação com OIGs do norte, quanto aquelas que sequer detêm mínimas condições financeiras e de gestão como um todo, sobrevivendo à custa de recursos públicos (Milani e Solinís, 2002).

No tocante à questão das ONGs do sul tenderem a desempenhar um papel de agente reprodutor e disseminador da concepção de desenvolvimento orientado pelas estratégias político-ideológicas das OIGs do norte, cabe discutir sobre a adequação de projetos de desenvolvimento elaborados com as preconcepções do "norte", mas para serem implantados nas heterogêneas 
realidades do "sul" (Dauvin, 2004). Segundo adverte Milando (2005), correse o risco de haver "cooperação sem desenvolvimento" nesses casos, por conta da ocorrência de uma espécie de desenvolvimento não desejado por uma determinada população ou por conta de um desenvolvimento institucionalizado que provoque a circulação de recursos e de profissionais especializados, sem que o resultado disso reverta para os beneficiários que motivaram a presença de uma ação de cooperação. Assim, a falta de atenção para com esses elementos pode vir a resultar, no extremo, em estatísticas falsas ou improváveis referentes ao desenvolvimento no mundo. Além disso, muitos programas seriam colocados em marcha sem uma análise de longo prazo, tendo em vista muito mais o cumprimento de prazos, os limites orçamentários e os aspectos jurídicos do que o alcance dos propósitos de um determinado projeto (Dauvin, 2004). Muitas vezes, algumas economias orçamentárias são realizadas com o intuito de fazer crer em uma gestão profissional do projeto (voltada para a eficiência e para a eficácia) (Dauvin, 2004; Freyss, 2004) e agradar a organização financiadora (com o intuito maior de a ONG gestora local do projeto se qualificar para projetos futuros) quando, na verdade, algumas possíveis perdas de cunho qualitativo podem resultar sobre o projeto.

Retornemos, então, à discussão inicial neste artigo em que se tratava da importância das especificidades locais, históricas, culturais, políticas e econômicas (Santos, 2005, 2009; Santos e Rodrígues, 2002) como fonte de mútua disponibilidade para o enriquecimento das culturas que compartilham um dado espaço social. A "multiculturalidade", como colocada por Santos (2009), remete a elementos que são caros a esta discussão na medida em que retoma algo fundamental: o posicionamento ideológico que, de um lado, impõe-se e, de outro, é aceito. Uma forma hegemônica de pensamento (a que Santos intitula "pensamento abissal") relega toda e qualquer outra forma de pensamento à inexistência ou a uma posição subalterna. Fazendo referência ao pensamento moderno ocidental como um pensamento abissal (embora reconheça que devam existir ou ter existido outras formas de pensamento abissal fora do Ocidente), destaca a profunda capacidade de produzir dualidades (verdadeiro/falso; ciência/"o desconhecido") e a impossibilidade da copresença dessas dualidades. A atitude neocolonialista (Dauvin, 2004) possível de ser encontrada nas relações e nas interações políticas e culturais protagonizadas pelo Ocidente nos dias de hoje seria, claramente, o reflexo desse pensamento dito "abissal". E, nesse caso de permanente tentativa de neocolonialismo, somente a luta por um pensamento "pós-abissal", isto é, uma mudança de referencial ideológico, poderia prover condições que dessem fim às falsas dicotomias e ao desconhecimento imposto (Santos, 2009). 


\section{Considerações finais}

Este artigo teve como finalidade maior a proposição de um olhar crítico e teórico sobre a governança da cooperação internacional para o desenvolvimento. Justifica-se esse interesse em razão da complexidade que cerca a temática, bem como por ser ainda um assunto pouco explorado pelo campo de conhecimentos da administração.

As estratégias relacionais envolvendo, por um lado, a participação de OIGs e ONGs do norte e, por outro lado, ONGs e OSCs do sul apresentam circunstâncias muito particulares em razão dos atores envolvidos e de sua representatividade na cena internacional. Relações de parceria ou de dependência, ou mesmo de condescendência, são dependentes de muitos fatores, como o poder financeiro, material e tecnológico, sem nunca esquecer as questões ideológicas que cercam estes intercâmbios.

A diferenciação em dois enfoques de desenvolvimento, assim como em duas principais visões da cooperação internacional, segundo Sánchez (2002), permitiu salientar o elemento ideológico que perpassa essas questões. Desse modo foi possível trazer uma visão alternativa e contra-hegemônica de desenvolvimento. Coube a Boaventura de Sousa Santos a maior parte do trabalho de analisar o horizonte e esmiuçar as mudanças que se apresentam já há certo tempo com respeito à globalização, exacerbada nos tempos atuais por conta de algumas de suas características, tais como a divisão centro/periferia, o cumprimento dos princípios de livre-mercado e dos regramentos acordados pelo Consenso de Washington. Boaventura, no entanto, traz a seus leitores a possibilidade de uma globalização contextualizada e de um desenvolvimento alternativo, o que vem enriquecer sobremaneira a forma de se enxergar o mundo, os atores e as relações entre todos.

Por fim, a governança da cooperação internacional, provavelmente, ainda irá gerar muitas controvérsias e discussões acadêmicas, pois termos com uma grande carga ideológica como governança, desenvolvimento e Estado, entre outros, na maioria das vezes, não encontram substitutos à altura. Como sugestão para contribuições futuras, estudos envolvendo casos particulares de cooperação internacional voltada para o desenvolvimento seriam de grande interesse do campo da administração, uma vez que a governança da cooperação internacional é algo que recém-começa a tomar forma em termos de estudos mais aprofundados fora das áreas de relações internacionais e de direito internacional. 


\section{Referências}

AFONSO, M.M.; FERNANDES, A.P. abCD Introdução à cooperação para o desenvolvimento. Lisboa: Instituto Marquês de Valle Flôr/Oikos, 2005.

AMORIM, C.L.N. Perspectivas da cooperação internacional. In: MARCOVITCH, J. (Org.). Cooperação internacional: estratégia e gestão. São Paulo: Edusp, 1994. p. 149-163.

ARNS, P.C. et al. Desenvolvimento institucional e articulação de parcerias para o desenvolvimento local. s.d. Disponível em: <www.pnud.org.br/arquivos/Desenv olvimento\%20Local\%20e\%20Articulacao\%20de\%20Parcerias.doc>. Acesso em: 7 abr. 2010.

ARTURI, C.; OLIVEIRA, R. Introdução. In: MILANI, C.; ARTURI, C.; SOLINÍS, G. (Org.). Democracia e governança mundial: que regulações para o século XXI? Porto Alegre: Universidade/UFRGS/Unesco, 2002. p. 266-291.

AYLLÓN, B. La cooperación internacional para el desarrollo: fundamentos y justificaciones en la perspectiva de la teoría de las relaciones internacionales. Carta Internacional, v. 2, n. 2, p. 32-47, out. 2007.

CAMPOS, T.L.C. Desenvolvimento, desigualdades e relações internacionais: uma introdução ao debate. In: CAMPOS, T.L.C. Desenvolvimento, desigualdades e relações internacionais. Minas Gerais: PUC Minas, 2005. p. 7-10.

CARRION, R.S.M.; LOPES, A.O. Desenvolvimento local e governança: o caso da central de comercialização de matéria-prima para o setor de reciclo em Porto Alegre. In: CARVALHO NETO, A.; NEVES, M.A.; FERNANDES, D.M. (Org.). Trabalho e cidades. Belo Horizonte: IRT/PUC Minas, 2004. p. 211-236.

COMISSÃO SOBRE GOVERNANÇA GLOBAL. Nossa comunidade global. Rio de Janeiro: FGV, 1996.

DAUVIN, P. Être un professionnel de l'humanitaire ou comment composer avec le cadre imposé. Tiers Monde, v. 45, n. 180, p. 825-840, 2004.

ESTEVA, G. Development. In: SACHS, W. (Ed.). The development dictionary: a guide to knowledge as power. London: Zed Books, 2007. p. 6-25.

FREYSS, J. La solidarité internationale, une profession? Ambivalence et ambiguïtés de la professionnalisation. Tiers Monde, v. 45, n. 180, p. 735-772, 2004.

FURTADO, C. O mito do desenvolvimento. Rio de Janeiro: Paz e Terra, 1974.

HALLIDAY, F. Repensando as relações internacionais. 2. ed. Porto Alegre: UFRGS, 2007.

HERZ, M.; HOFFMANN, A.R. Organizações internacionais: história e práticas. Rio de Janeiro: Elsevier, 2004. 
LIMA, A.C.S. Notas (muito) breves sobre a cooperação técnica internacional para o desenvolvimento. In: SILVA K.C.; SIMIÃO, D.S. (Org.). Timor-Leste por trás do palco: cooperação internacional e a dialética da formação do Estado. Belo Horizonte: UFMG, 2007. p. 417-425.

MILANDO, J. Cooperação sem desenvolvimento. Lisboa: ICS, 2005.

MILANI, C. La globalisation, les organisations internationales, le débat sur la gouvernance. In: GEMDEV (ouvrage collectif). Mondialisation: les mots et les choses. Paris: Karthala, 1999.

MILANI, C.; SOLINÍS, G. Pensar a democracia na governança mundial: algumas pistas para o futuro. In: MILANI, C.; ARTURI, C.; SOLINÍS, G. (Org.). Democracia e governança mundial: que regulações para o século XXI? Porto Alegre: Universidade/UFRGS/Unesco, 2002. p. 266-291.

MINISTÉRIO DAS RELAÇÕES EXTERIORES (MRE). Agência Brasileira de Cooperação (ABC). Brasil tem novo perfil nas relações internacionais. 2008. Disponível em: $<$ www.abc.gov.br/lerNoticia.asp?id_Noticia=451>. Acesso em: 8 abr. 2010.

NAVARRO-FLORES, Olga. Les relations de partenariat Nord-Sud: du paradoxe au compromis - une approche institutionnaliste des relations entre ONG dans le secteur de la coopération internationale. 2007. $341 \mathrm{f}$. Tese (doctorat en gestion) — École des Sciences de la Gestion, Université du Québec à Montréal, Montréal, 2007.

ROSTOW, W.W. Etapas do desenvolvimento econômico: um manifesto não comunista. Zahar: Rio de Janeiro, 1974.

SÁNCHEZ, E.R. Cooperación y desarrollo: nueve preguntas sobre el tema. Burgos, España: Amycos. Disponível em: <www.ciberoamericana.unican.es/documentos/ introcoopdes/Cooperación\%20y\%20desarrollo.\%20Nueve\%20pregunas\%20sobre \%20el\%20tema.pdf>. 2002. Acesso em: 8 abr. 2010.

SANTOS, B.S. (Org.). A globalização e as ciências sociais. São Paulo: Cortez, 2005.

SANTOS, B.S. Para além do pensamento abissal: das linhas globais a uma ecologia de saberes. In: SANTOS, B.S.; MENESES, M.P. (Org.). Epistemologias do sul. Coimbra: Almedina/CES, 2009. p. 23-71.

SANTOS, B.S.; RODRÍGUES, C. Introdução: para ampliar o cânone da produção. In: SANTOS, B.S. (Org.). Produzir para viver. Rio de Janeiro: Civilização Brasileira, 2002. p. 23-77.

TUCKER, V. The myth of development. A critique of a eurocentric discourse. In: MUNCK, R.; O'HEARN, D. (Ed.). Critical development theory: contributions to a new paradigme. London: Zed Books, 1999. p. 1-26. 